\title{
Development of the Future Mathematics Teachers' Constructive Skills
}

\author{
Roza A. Valeeva \& Kadriya B. Shakirova \\ Kazan Federal University, RUSSIA
}

•Received 17 June 2015• Revised 22 August 2015•Accepted 19 September 2015

\begin{abstract}
The aim of modern vocational education is the development the individual who is flexible enough to adapt to changing situations, is able to independently acquire the necessary knowledge, and the skill to put them into practice to address a variety of emerging issues. The future specialist should think critically, be able to see emerging real world problems, and to look for rational solutions. He must work competently with information, have abilities to collect the necessary facts in order to solve a particular problem, analyze them, and make reasonable conclusions. This article deals with the development of mathematics teachers' constructive skills during the process of their methodological training, which is closely connected to the informational, explicating, and stimulating functions of a teacher. The article describes features of the constructive skills. The specificity is revealed and definition is given to the key concept of the research, namely "constructive skills". This paper deals with the forms and methods of the mathematics teachers' constructive skills development. The article presents the results of experimental work on the mathematics teachers' constructive skills development. The materials of this article may be of use to those who are interested in the research of methodology of mathematics teachers' skills training and to the instructors teaching mathematics at different educational establishments.
\end{abstract}

Keywords: mathematics, mathematics teacher, a constructive function, constructive skills, designing activity, structuring educational material, technology training of future teachers

\section{INTRODUCTION}

\section{Actualization of the problem}

The student's holistic comprehensive development, the formation of personality and professional development is not possible without a high level of mathematical training. The most important type of educational activity is the solution of tasks, which allows students to assimilate mathematical theory, and to develop creativity and independent thinking. According to Sarantsev (2005), mathematics tasks are the main means of students' knowledge and skills formation, their development and means of organizing training activities. As a result, the effectiveness of the educational

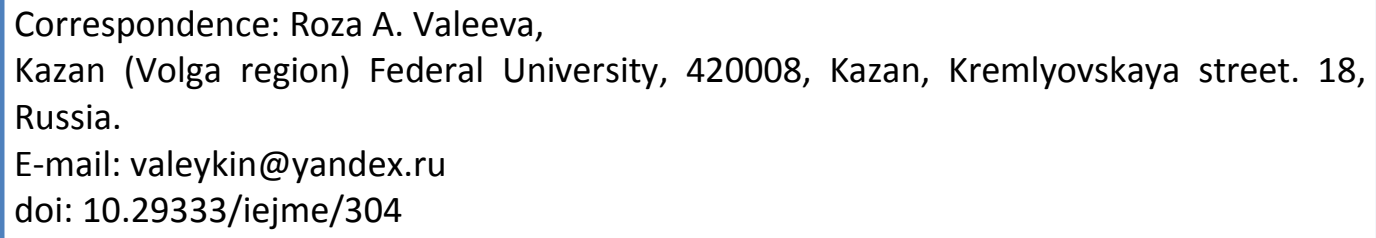


process largely depends on the choice of tasks, and the teaching of students to solve them.

Not only does the importance of the task systems necessitate the formation of future mathematics teachers' skills of their design. The main reason is the lack of ready-made systems of tasks for the lesson. Even if the authors of textbooks provide a system of tasks, while selecting tasks for the lesson the teacher in effect destroys them. Based on our analysis of the collection of tasks and textbooks, we can conclude that the examples of related tasks in the methodological literature are illustrative for achieving specific purposes (study of certain topics, the formation of pupils' concrete ability and using it at some stage of the training).

However, they are hardly suitable for the preparation to the lesson realizing a specific goal, formulated by taking into account the specificities and the level of training, the individual characteristics of a particular class of students, the difficulties of studying the previous topics. System of tasks built by another author may not always be successfully used by an established math teacher, because it does not account for his individual characteristics and style of teaching.

The variety of textbooks, the constant change of the school curriculum in mathematics, the inclusion of additional topics, the change in emphasis in the study of individual questions and entire sections dictate the need for continuous improvement of the existing tasks. Thus, the finished system of tasks can only serve as a basis for further reforms in line with the objectives, characteristics of students in the class and the teacher's personality. In other cases, the teacher must have the skills to construct them.

\section{Theoretical background}

Analysis of the psychological and pedagogical literature allowed us to determine the circle of those issues and problems that are resolved in the methods of teaching mathematical problem solving. Psychological and pedagogical aspects of solving tasks process are presented in the works of Ball ((1990), Friedman \& Turetskiy (1989), Gurova (1976), Halperin (1966), Davydov (1966), Okon' (1968), Zagvyazinsky (1982), Kulyutkin (1971), Lerner (1981), Matyushkin (1972), and Makhmutov (1975).

Within the general methodology of solving tasks, the issues of content selection of the material and its distribution within topics; scheme for solving the problem; classification tasks; the problem of finding task solutions; the formation of cognitive activity, cognitive interest, properties and qualities of the students in the process of task solving (Boltyanskii \& Hochberg, 1965; Episheva, 1997; Kolyagin, 1977; Erdniev, 1965; Metel'skii 1982; Lyapin, 1965). The issues of training students for solving specific types of mathematical problems belong to the partial techniques (Krupich, 1995; Sarantsev, 2005).

Teachers, psychologists and methodologists have shown that for effective implementation of the goals of education, we should use the tasks system with evidence-based structure in the educational process, in which the places and order of each item are strictly defined and reflect the structure and function of these tasks.

Each task in itself is usually some isolated assertion or requirement and includes a specific action to address it. However, the teacher, putting the task in front of students, as a rule pursue more general objectives. Specific task is for him a separate element in the tasks system to achieve broader goals - the formation or consolidation of a new concept, to obtain new or the revitalization of old knowledge, demonstration a particular method of reasoning, activation methods for proving theorems outlined in the course (Dorofeev, 1983). 


\section{Status of the problem}

Analysis of psychological and educational literature allowed us to draw the conclusion that researchers still are not clearly distinguishing the concept of "mathematics teachers' constructive skills".

Currently, the Russian pedagogical science distinguishes the following approaches to this concept.

The first group of theoretical assumptions perform research on systems design tasks, and their use in the school practice of teaching mathematics. Kalinkina (1995) considers dynamic tasks as a means of improving geometry teaching in high school. Georgiev (1988) summarizes the experience of activation of students through the use of the task complexities. Egulemova (2003) alters geometry tasks for the development of the basic school pupils' cognitive interest. Levashov (2003) studies the use of multi-level tasks for differentiated work with students. Kononenko (2002) considers tasks as the means of formation of pupils' constructive abilities while studying the course of plane geometry. Muravin (1988) develops principles of the system of exercises in algebra in junior high school, whilst Buslaev (2002) highlights the methodological basis of tasks selection in mathematics for high school students of different profiles. These studies convince of the efficiency of using tasks systems in learning math, and make a significant contribution to the theory and methodology of teaching the subject through a system of tasks. This proves the necessity of forming the future mathematics teachers' ability to design tasks systems.

The second group includes studies on training future mathematics teachers in pedagogical universities by solving tasks on special subjects. In particular, Mordkovich (1986) reveals the professional-pedagogical orientation of special training for mathematics teachers at the Pedagogical University. Buzulina (2002) examines the role and place of uncertain tasks in classes of analytic geometry.

The third group of theoretical assumptions includes those research revealing some aspects of formation of the future mathematics teachers' skills to design the tasks system. Dyumina (2006) defines a substantial component of a methodical system of training future mathematics teachers to design tasks systems. Orlyanskaya (2004) offers to form future mathematics teachers' constructive skills by building tasks systems of different levels of organization. Astakhova (2009) develops teaching compilation tasks methods for future mathematics teachers.

However, despite the importance of the research results on the problem of future mathematics teachers' skills to design tasks systems formation, many questions remain undeveloped. A holistic approach to teaching tasks systems constructing has not been developed. It is necessary to reveal the role and place of training tasks systems construction in training future mathematics teachers. It's also urgent to clarify the objectives and content of the training, coordination of the issues of constructing with the content of methodological cycle disciplines, and to improve the forms and methods of teaching.

\section{Constructive abilities}

The teacher's professional work is connected with carrying out a number of functions. Russian scientists Kuzmina (1985), Slastenin \& Podymova (1997), Markova (1993), and Mitina (1994) define the structural, organizational, communication, informative, developing, and stimulating and gnostic functions of a teacher. At the same time, all the researchers emphasize the importance of the constructive function, as it relates to the analysis and design of the learning process as a whole, as well as construction of the individual components of this process: objectives, contents, 
methods, forms and means of instruction. The studies by Choshanov (2011) are devoted to the didactic engineering including the analysis, design, modeling, designing as its elements.

Due to the transition of educational institutions to the new Federal State Educational Standards (FSEF), to the need of improving the quality of school mathematics education in general, and train students for final certification in particular, there is a need for a teacher in a special structuring of educational material, and in the construction of an efficient system of methods and forms of education. Formation and development of the teacher's constructive abilities begins at the university.

The teacher's constructive function includes the following main types of planning activity:

- Constructive-target, involves analysis of training standards, requirements for students' knowledge and skills and designing on this basis the objectives of training, development and education in the process of studying the subject;

- Constructive-contents, is the selection and design of the content of educational material, thematic and lesson scheduling;

- Constructive-procedure meaning the design of methods, forms and means of education, and the structure and sequence of the teacher and students' activity in the classroom;

- Constructive-assessment consisting in designing an effective system of monitoring and evaluation of students' educational activity (Mishin, 1993, pp.41-42).

We define the constructive skills as the mathematics teacher's professional ability allowing to transform knowledge of mathematics teaching methods into the pedagogical tool that provides content for the construction of the particular stage of learning.

The structure of the constructive skills is represented by the following components:

- Orientation (the ability to update knowledge in the constructive activity);

- Operating (the ability to structure the content, convert it, and design);

- Modification (determination of possibilities of varying elements to achieve teaching objectives, the effectiveness of the method design depending on the type and stage of the lesson) (Kovaleva, 2012).

\section{MATERIALS AND METHODS}

\section{The aim and tasks of the research}

The aim of this paper is a theoretical overview of some elements of training future mathematics teacher to implement a constructive role while studying the course "Methods of teaching mathematics."

\section{Theoretical and Empirical Methods}

In compliance with the goal, the following methods have been selected:

- Theoretical: analysis of pedagogical and psychological literature; study and generalization of innovative pedagogical experience, analysis, synthesis;

- Empirical: participant observation, tests, interviews, conversations.

\section{The trial infrastructure and stages of the research}

The study involved 144 students from Kazan Federal University, pedagogical department of the Institute of Mathematics and Mechanics, as named after N.I. Lobachevsky.

The study was conducted in three stages: 
The first stage created an experimental platform at the Institute of Mathematics and Mechanics; the program, plus educational and thematic plans for teaching students techniques developed and implemented in the educational process.

In the second stage, the analysis of students' training programs was carried out, and the implementation of the formation of constructive skills.

In the third stage the program was developed and tested. We summarize the results of the pedagogical experiment to test the effectiveness of a technique of constructive skills formation. The control stage of the experiment was aimed at identification of the result of the work conducted.

In the course of ascertaining experiment plans, summaries of lessons, individual fragments of lessons prepared by the students for the first laboratory work at the discipline "Theory and technique of teaching mathematics in specialized classes" were analyzed. Students were encouraged to specify the following:

- To analyze the system of exercises to any topic in mathematics, proposed by the author of the textbook;

- To arrange tasks in order of increasing difficulty;

- To choose differentiated tasks;

- To choose the targets agreed with the didactic purposes of different stages of training;

- To choose the problems leading to the formulation of properties, rules, theorems, and algorithms, etc.

The basic shortcomings, mistakes and difficulties in a constructive activity of students included: difficulty in the formulation of precise purpose of the lesson and, as a consequence, the weak link of the lesson's content for this purpose. Ascertaining experiment showed that a special training of future teachers to design the content of the mathematics teaching in general, and tasks systems, in particular is required. There is also a direct link between the level of general mathematical training of students and the level of their design skills.

Forming experiment consisted of training the future mathematics teachers' constructive activity and design skills.

After the forming experiment, the summaries of lessons conducted in the period of teaching practice and the lessons themselves were also analyzed.

\section{RESULTS}

In the undergraduate curriculum of the program "Mathematics, Computer Science and Information Technologies" the discipline "Methods of teaching mathematics" is studied for three semesters and precedes the teaching practice. During the teaching practice, students have to plan lessons and extra-curricular activities. This activity needs a certain level of constructive skills. Formation of the future teachers' constructive abilities can be considered as one of the main objectives of their methodical training. The teacher must be able to design training material, which involves a combination of different forms of knowledge representation, systems of exercises that promote the absorption of the main structural elements of mathematics: concepts, theorems, problems, and methods of action.

The main phase of construction is the structuring of educational material. It is aimed at identifying the internal semantic relations of the studied information. The educational material may be structured "successively" and "parallel". The first method corresponds to the traditional study of the subject, when the topic is developed over a few lessons. The second method allows to study the whole topic during a single school lecture. This is particularly important in studying the discipline of "Mathematics", without division into algebra and geometry. The study of these 
branches of mathematics is organized using the method of "immersion": for some interval of time, only algebra is studied, then geometry.

For example, the theme of "Parallel lines and planes in space" in the course of solid geometry in the 10th grade is studied in the following logic: first a pair of geometric objects (two straight lines and planes, two planes) are considered and then - various cases of their mutual arrangement. Considering these cases, students can formulate their own definition of objects concurrency, and then the teacher leads to the formulation of their signs. All this instructional information can be written on a single sheet (the plane of the board), using the so-called "parallel method of printing". Longterm observations show that this method of structuring the educational material is new for the students themselves. It allows them to see the overall logic of this theory, to understand the universal connection of things and phenomena. This example is also revealing in terms of "self-developing knowledge", when one knowledge leads to another. In the same way, you can structure the training material of the theme "Perpendicular lines and planes in space".

Consideration of structuring educational information precedes the task for the students: compile and organize knowledge on the topic "The mutual arrangement of lines and planes in space". The method of "inverted learning" is used. Initially the task is proposed job without pedagogical instruction. Then, new approaches to the solution of this methodological problem are set out. Basically, students offer a consistent repetition, which is difficult to trace the general logic of the topic study.

To prepare for the laboratory work, students are offered the task, aimed at forming constructive skills. Here again, the method of "inverted learning" is used. First, students are assigned tasks on the development of fragments of lessons, without detailed instructions for its implementation. In preparation for the lesson, they act on intuition, remembering the actions of their teachers at school.

For example, having been instructed to develop a fragment of a lesson in the 10th form entitled "Intervals Method" using the textbook "Algebra and analysis" (Kolmogorov, 2004), students outline the text of the textbook and copy it, without changing the position or sequence of educational material or examples discussed there. The question arises: What is a teacher? Can't the pupils themselves read a textbook at home? What about updating, motivation?

As a result of this approach to teaching students, the design of educational material, when the student has already thought about the methodological problem confronting him, his interest in this issue starts to form. Together with the teacher, he reveals the basic principles and requirements for the selection and design of educational material (the link between old and new knowledge, the choice of the socalled focus example, and the motivation of introducing a new concept or mode of action, the knowledge required to master new, etc.). The teacher, together with the students, analyze an option fragment of the lesson, enabling them to achieve its goals. Students' reflective work is an important stage of their professional training (Biktagirova \& Valeeva, 2014).

In the following example, the method is used to solve intervals inequalities. Therefore, it is advisable to remember how to solve quadratic inequalities when the left side is already present as a product of two factors. This method can be a parabola, or the transition to the two systems of linear inequalities. The teacher then proposes to solve the inequality, the left part of which consists of the product of three linear factors. Possible solution is drawing up four systems, each of which contains a four linear multiplier. But it's a much too time-consuming way. Then the teacher suggests inequality containing the product of a sufficiently large number of linear factors and, surprisingly, his students solves it. Students are subjected to verification of his decision. The goal achieved, and students' cognitive interest was shown. They are ready to master a new way of dealing with inequalities. Further, it is possible to give theoretical basis of this method to study the properties of continuous functions, the 
formulation and proof of the theorem. And only after all this, you can make out an example from which to start exposition of the method of intervals in the textbook.

As a result of laboratory studies on designing lessons fragments, forming new concepts, studying theory, and new methods of action, the students' readiness level to design training content changes from reproductive to part-search level. Future math teachers will not seek to summarize the textbook, but try to design a learning process: build on the personal experience of students, move from previously learned material to the new one, to motivate the study of a new theorem, new method of solving the task.

One of the main practical methods of teaching mathematics is exercises. Training students to design exercises systems is necessary because the system developed by the authors of textbooks in planning the lesson is often destroyed or does not always correspond to the level of students' readiness, their interests, requests, and does not take into account the class characteristics and the teacher's teaching style. The experiment conducted confirmed that the students select the exercises for a lesson "through one". Students find it difficult to justify the expediency of any given assignment. Therefore, some laboratory studies on the method of mathematics teaching are devoted specifically to design a system of exercises that allow to generate any mathematical concept or methods of training actions.

Tasks for designing systems of exercises can be performed at different levels: reproductive, reproductive and creative, creative and reproductive and creative level. The first stage is to review the finished system of exercises, and to reveal a didactic sense of each task. The next step is to choose exercises that carry a certain didactic load (the introduction of concepts, propaedeutic, leading and others). Further, the students make their own system of exercises within the specified parameters. There are such tasks of working with exercises: to arrange sequentially increasing degree of difficulty; to create differentiated tasks (split-level job to pick the topic).

\section{DISCUSSION}

Classroom on the methods of mathematics teaching is focused on training students for independent designing of the educational material. Readiness for this activity implies the following abilities:

- To select the required educational material;

- To build it into a certain logical sequence;

- To set goals and learning objectives;

- To choose effective forms and methods of training, allowing for the realization of goals and objectives;

- To anticipate the difficulties and mistakes of students while studying the topic;

- To link the new material with that previously studied, and to establish interdisciplinary communication.

Methodology of the future mathematics teachers' constructive skills formation is as follows:

- Formation of positive motivation to master the appropriate skills (updated during teaching practice);

- Acquaintance with different ways of structuring teaching materials, as a fundamental element of known techniques of mathematics teaching: technology integration of didactic units by Erdniev (1992), technology of modular training by Choshanov (1996), problem-based learning technologies by Makhmutov (1975);

- Independent work on the structuring of educational material, the design of the individual elements of learning and the whole process; 
- Testing and correction of appropriate skills in the period of teaching practice.

\section{CONCLUSION}

This course of methods of teaching mathematics will ensure the development of future math teachers' constructive skills if:

- This problem is considered as one of the priority tasks of training;

- It equips students with the supporting knowledge of the constructive work of the teacher and its components;

- It will be developed as a special tasks system, aimed at the formation and development of design skills;

- It involves students in self-constructive activity. The criterion for the students to achieve a certain level of development of these skills will be their professional worth in the period of teaching practice.

\section{ACKNOWLEDGMENTS}

The work is performed according to the Russian Government Program of Competitive Growth of Kazan Federal University.

\section{REFERENCES}

Astakhova, N.A. (2009). Methods of teaching future mathematics teachers of drafting tasks. Doctoral dissertation. Volgograd.

Ball, G.A. (1990). The theory of learning tasks: Psycho-pedagogical aspect. Moscow: Pedagogika.

Biktagirova, G.F., \& Valeeva, R.A. (2014). Development of the teachers' pedagogical reflection. Life Science Journal, 11(9s), 60-63.

Boltyanskii, V.G., \& Hochberg, I.Ts. (1965). Theorems and problems of combinatorial geometry. Moscow: Nauka.

Buslaev, A. (2002). Methodological basis of tasks selection in mathematics for high school students of different profiles of training. Doctoral dissertation. Moscow: MPSU.

Buzulina, T.I. (2002). Vague tasks in the training of future mathematics teachers. Doctoral dissertation. Rostov-on-Don: VSPU.

Choshanov, M.A. (1996). Flexible technology of problem-modular education. Moscow: Naronoye obrazovanie

Choshanov, M.A. (2011). Didactics and Engineering. Moscow: BINOM.

Davydov, V.V. (1966). The theory of developmental education. Moscow: INTOR.

Dorofeev, G.V. (1983). On drawing the cycles of interrelated tasks. Mathematics in school, 3, 34-38.

Dyumina, T.Y. (2006). The substantial component of methodical system of the future mathematics teachers training to design tasks systems. Doctoral dissertation. Volgograd.

Egulemova, N.N. (2003). Modification of geometric problems as means of the development of the basic school pupils' cognitive interests. Doctoral dissertation. Orel: OSU.

Episheva, O.B. (1997). General methods of teaching mathematics in high school Tobolsk: TGPI named after D.I. Mendeleev.

Erdniev, P.M. (1965). Technique of exercises on arithmetic and algebra. Moscow: Prosvescheniye.

Erdniev, P.M. (1992). Integration of didactic units as training technology. Moscow: Prosvescheniye.

Friedman, L.M., \& Turetskiy, E.N. (1989). How to learn to solve tasks. Moscow: Prosvescheniye.

Georgiev, V. (1988). Experience of activation schoolchildren based on the use task cycles. Mathematics in school, 1, 77-78.

Gurova, L.L. (1976). Psychological analysis of tasks solving. Voronezh: Voronezh State University.

Halperin, P.J. (1966). Psychology of thinking and teaching about the gradual formation of mental actions. In: Studies of thinking in Soviet psychology. Moscow: Nauka. 
Kalinkina, T.M. (1995). Dynamic tasks as means of improving the process of teaching geometry in high school. Doctoral dissertation. Saransk: MSPI named after M.E. Evseviev

Kolmogorov, A.N. (Ed.) (2004). Algebra and analysis. The textbook for 10-11 classes of educational institutions. Moscow: Prosvescheniye.

Kolyagin, Y.M. (1977). Tasks in teaching mathematics. Moscow: Prosvescheniye.

Kononenko, N.V. (2002). Tasks system as means of pupils' constructive abilities formation while studying a school course of plane geometry. Doctoral dissertation. Chita: ZSPU.

Kovaleva, G.I. (2012). Methodical system of training of future mathematics teachers to design tasks systems. Doctoral dissertation. Volgograd: VSSPU.

Krupich, V.I. (1995). Theoretical basis of training to solve mathematical tasks. Moscow: Prometey.

Kulyutkin, Y.N. (1971). Individual differences in mental activity of adult learners. Moscow: Pedagogika.

Kuzmina, N.V. (1985). Abilities, giftedness, and talent of a teacher. Leningrad: Znanie.

Lerner, I.J. (1981). Didactic bases of training methods. Moscow: Pedagogika.

Levashov A.M. (2003). Multi-level tasks as means differentiated instruction in small classes [in Physics lessons at the village school]. Physics in the school, 1, 30-32.

Lyapin, S.E. (Ed.) (1965). Methods of teaching mathematics in the 8-year school. Moscow: Prosvescheniye.

Makhmutov, M.I. (1975). Problem teaching: the basic questions of the theory. Moscow: Pedagogika.

Markova, A.K. (1993). Psychology of teacher's labor. Moscow: Prosvescheniye.

Matyushkin, A.M. (1972). Problem situations in thinking and learning. Moscow: Pedagogika.

Metel'skii, N.V. (1982). Didactics of Mathematics: General procedure and its problems. Minsk: Publishing house of BSU.

Mishin, V.I. (Ed.) (1993). Practice on teaching mathematics at high school. Moscow: Prosvescheniye.

Mitina, L.M. (1994). The teacher as a person and a professional. Moscow: Delo.

Mordkovich, A.G. (1986). Professional and pedagogical orientation of special training of mathematics teacher at the Pedagogical Institute. Moscow: Moscow State Pedagogical Institute.

Muravin, G.K. (1988). The principle of building a system of exercises on algebra in junior high school. Doctoral dissertation. Moscow.

Okon', V. (1968). Basics of problem-based learning. Moscow: Prosvescheniye.

Orlyanskaya, O.N. (2004). Technique of the future mathematics' teacher's skills to design tasks systems formation. Doctoral dissertation. Volgograd.

Sarantsev, G.I. (2005). Exercises in teaching mathematics. Moscow: Prosvescheniye.

Slastenin, V.A., \& Podymova, L.S. (1997). Pedagogy: innovative activity. Moscow: Magistr.

Zagvyazinsky, V.I. (1982). Methodology and methods of didactic study. Moscow: Pedagogika.

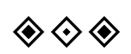

